University of Nebraska - Lincoln

DigitalCommons@University of Nebraska - Lincoln

USGS Staff - Published Research

US Geological Survey

2010

\title{
Trail Pheromone Disruption of Argentine Ant Trail Formation and Foraging
}

\author{
David Maxwell Suckling \\ New Zealand Institute for Plant and Food Research Limited, max.suckling@plantandfood.co.nz \\ Robert W. Peck \\ University of Hawaii at Hilo \\ Lloyd D. Stringer \\ New Zealand Institute for Plant and Food Research Limited \\ Kirsten Snook \\ University of Hawaii at Hilo \\ Paul C. Banko \\ U.S. Geological Survey
}

Follow this and additional works at: https://digitalcommons.unl.edu/usgsstaffpub

Suckling, David Maxwell; Peck, Robert W.; Stringer, Lloyd D.; Snook, Kirsten; and Banko, Paul C., "Trail Pheromone Disruption of Argentine Ant Trail Formation and Foraging" (2010). USGS Staff -- Published Research. 640.

https://digitalcommons.unl.edu/usgsstaffpub/640

This Article is brought to you for free and open access by the US Geological Survey at DigitalCommons@University of Nebraska - Lincoln. It has been accepted for inclusion in USGS Staff -- Published Research by an authorized administrator of DigitalCommons@University of Nebraska - Lincoln. 


\title{
Trail Pheromone Disruption of Argentine Ant Trail Formation and Foraging
}

\author{
David Maxwell Suckling • Robert W. Peck • \\ Lloyd D. Stringer • Kirsten Snook • Paul C. Banko
}

Received: 23 August 2009 /Revised: 2 December 2009 /Accepted: 17 December 2009/Published online: 14 January 2010

(C) Springer Science+Business Media, LLC 2010

\begin{abstract}
Trail pheromone disruption of invasive ants is a novel tactic that builds on the development of pheromonebased pest management in other insects. Argentine ant trail pheromone, (Z)-9-hexadecenal, was formulated as a microencapsulated sprayable particle and applied against Argentine ant populations in $400 \mathrm{~m}^{2}$ field plots in Hawai'i Volcanoes National Park. A widely dispersed point source strategy for trail pheromone disruption was used. Traffic rates of ants in bioassays of treated filter paper, protected from rainfall and sunlight, indicated the presence of behaviorally significant quantities of pheromone being released from the formulation for up to 59 days. The proportion of plots, under trade wind conditions $\left(2-3 \mathrm{~m} \mathrm{~s}^{-1}\right)$, with visible trails was reduced for up to 14 days following treatment, and the number of foraging ants at randomly placed tuna-bait cards was similarly reduced. The success of these trail pheromone disruption trials in a natural ecosystem highlights the potential of this method for control of invasive ant species in this and other environments.
\end{abstract}

D. M. Suckling $(\bowtie) \cdot$ L. D. Stringer

The New Zealand Institute for Plant and Food Research Limited, PB 4704, Christchurch, New Zealand

e-mail: Max.Suckling@plantandfood.co.nz

R. W. Peck $\cdot$ K. Snook

Hawai'i Cooperative Studies Unit,

Pacific Aquaculture and Coastal Resources Center,

University of Hawai'i at Hilo,

Hawai`i National Park, HI 96718, USA

P. C. Banko

U.S. Geological Survey,

Pacific Island Ecosystems Research Center,

Hawai'i National Park, HI 96718, USA
Keywords Argentine ant · Trail pheromone · Disruption · Trail integrity $\cdot$ Invasive species

\section{Introduction}

The Argentine ant, Linepithema humile (Mayr), is a highly invasive species that has numerous negative impacts on native arthropods (Gillespie and Reimer 1993; Human and Gordon 1997; Liebherr and Krushelnycky 2007), including other ant species (Human and Gordon 1996; Holway 1999). When a species such as L. humile invades remote islands or other ecologically sensitive areas, native arthropod populations may be eliminated quickly causing problems for other organisms, such as plants, which may lose their native pollinators (Cole et al. 1992) and seed dispersers (Christian 2001). In human-modified landscapes, Argentine ants are both a nuisance (Vega and Rust 2001; Holway et al. 2002) and an agricultural pest, impacting the effectiveness of biological control agents in orchards (Moreno et al. 1987; Itioka and Inoue 1996). Poison baits have not proven entirely reliable for control of these pests (e.g., Krushelnycky and Reimer 1998; Hooper-Bui and Rust 2000; Klotz et al. 2000; Greenberg et al. 2006) and also pose risks to pets and wildlife. Thus, more effective and environmentally benign control tactics are needed for the management and control of these invasive ants.

Sensitive ecosystems require appropriate pest-control formulations to avoid non-target impacts at the landscape level. Pheromone-based pest management (e.g., El-Sayed 2009) offers both target specificity and low hazard. This approach could be used for managing invasive ants, such as Argentine ants, in urban or natural ecosystems. To date, exploration of the potential for using pheromones or other odorants for control of ant species has been limited 
mainly to leaf cutting ants (Robinson and Cherrett 1978), the red imported fire ant (Solenopsis invicta), and the Argentine ant (Robinson and Cherrett 1978; Shorey et al. 1992).

Argentine ants use a trail pheromone, consisting of ( $Z$ )9-hexadecenal (Z9-16:Ald) (Cavill et al. 1979), to orient to food and communicate the location of food to nest mates. The compound Z9-16:Ald also is a sex pheromone component of a number of moth species (El-Sayed 2009) and is readily available commercially. Wright (1964) first proposed the use of synthetic pheromones for mating disruption of moths, but until recently there has been no effort to expand this concept to flightless insects, such as foraging ants, through trail pheromone disruption.

Trail-following behaviors of Argentine ants have been well examined (Van Vorhis Key et al. 1981; Van Vorhis Key and Baker 1982). Van Vorhis Key and Baker (1982) recognized that it might be possible to modify trail following behavior by using synthetic compounds, although they did not elaborate on a possible method. The recent demonstration of close-range disruption of Argentine ant trails by using pheromone contained in "twist-tie" polyethylene tubing dispensers showed reduced ant traffic in small plots (Tatsuki et al. 2005; Tanaka et al. 2009). This type of polyethylene-tubing formulation has been used for mating disruption of moths, usually at a density up to one thousand discrete point sources per hectare in orchards and other crops (Suckling and Angerilli 1996; Suckling 2000). However, a discrete point-source approach may not give an effective concentration of trail pheromone to prevent trail following over large areas, except under very still conditions, because pheromone concentration from these dispensers is a function of application height (Suckling et al. 1999). Moreover, the boundary layer, which is the target for trail disruption of ants, is likely to receive the lowest concentration of pheromone.

In previous work, we quantified the integrity of Argentine ant trail-following behavior by video analysis of movement and track angles (Suckling et al. 2008). Trail integrity, defined as $r^{2}$ for the position of ants in a video frame, was devised as a measure of the ability of workers to follow a reasonably straight trail, before and after the application of a point source of synthetic trail pheromone. Well-formed trails were completely disrupted indoors by using a crude wax-based formulation. However, due to rapid pheromone release from the wax-coated quartz sand, only several hours of disruption was achieved in small $\left(1 \mathrm{~m}^{2}\right.$ and $\left.4 \mathrm{~m}^{2}\right)$ plots (Suckling et al. 2008).

In this study, we examined whether a more durable, sprayable formulation, containing Z9-16:Ald, could be used to disrupt trail-following behavior of Argentine ants in a hot and windy field setting. We used a widely dispersed pointsource strategy within the boundary layer where the ants were actively foraging. A micro-encapsulated formulation was chosen for testing because a similar product is commercially available for mating disruption of moth species (Stelinski et al. 2007). The research followed two approaches: 1) laboratory bioassay and micro-plot testing of short-range disruption of trail-following behaviors, and 2) larger field trials to examine impact of disruption on trail formation and recruitment to baits.

\section{Methods and Materials}

Chemicals (Z)-9-Hexadecenal (94\% isomeric purity) was obtained from Bedoukian Research (Danbury, CT, USA) and formulated into a micro-encapsulated sprayable product. The pheromone formulation was prepared by Suterra LLC (Bend, OR, USA), and was similar to that used for light brown apple moth in California (www.cdfa.ca.gov) and other moths (Stelinski et al. 2007), with ca $20 \%$ active ingredient as micro-encapsulated particles in water. This formulation had the advantage of being readily dispersible in the field with relatively even coverage of pheromone in the plots.

Field Site The field study took place at ca $1,200 \mathrm{~m}$ elevation in an exposed landscape with high Argentine ant populations, windy conditions, and occasional heavy rainfall, on friable cinder soil and rock. The area of Hawai' $\mathrm{i}$ Volcanoes National Park called Broomsedge Burn (19 $25^{\prime}$ $59.6^{\prime \prime} \mathrm{N}, 155^{\circ} 17^{\prime} 35.2^{\prime \prime} \mathrm{W}$; Fig. 1) is mesic to dry ohia (Metrosideros polymorpha) woodland now dominated, after fires, by the invasive grasses broomsedge bluestem (Andropogon virginicus) and bush beardgrass (Schizachyrium condenstum). It is exposed to prevailing trade winds,

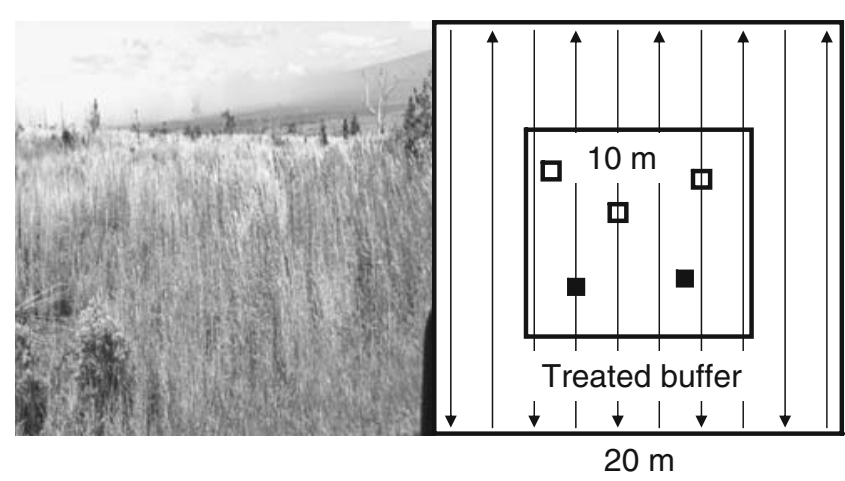

Fig. 1 Layout for trial testing the application of micro-encapsulated Argentine ant trail pheromone, $(Z)-9$-hexadecenal, in Moana Loa in Hawai'i Volcanoes National Park (left), showing $400 \mathrm{~m}^{2}$ plots treated by 10 swathes using a garden sprayer. Ant trailing and foraging at bait cards were made in the central square ( $5 \mathrm{~m}$ from the plot boundary). Locations were either fixed (black squares) at the same location, or randomly (unfilled squares) located within the assessment area on each sampling date 
averaging 2-3 $\mathrm{m} \mathrm{s}^{-1}$, because of sparse canopy cover (Suckling et al. 2008). During the trial, daytime air temperatures of $15-29^{\circ} \mathrm{C}$ (mean $20.4^{\circ} \mathrm{C}$ ) and ground temperatures of $13-30^{\circ} \mathrm{C}$ (mean $20.1^{\circ} \mathrm{C}$ ) were experienced. Wind speed at $1 \mathrm{~m}$ above ground level ranged from 0.3 to $3.7 \mathrm{~m} \mathrm{~s}^{-1}$ (mean $1.5 \mathrm{~m} \mathrm{~s}^{-1}$ ), while at ground level $(1 \mathrm{~cm})$ wind speed ranged from 0 to $2.4 \mathrm{~m} \mathrm{~s}^{-1}$ (mean $0.9 \mathrm{~m} \mathrm{~s}^{-1}$ ).

Pre-treated Micro-plot Disruption We anticipated that forager numbers would be reduced under pheromone disruption conditions. A dose-response experiment was conducted over a square of paper on aluminum foil-covered boards $(21.5 \times 21.5 \mathrm{~cm})$. The papers were treated with 0 , $3.7,37.5,375$, or $3,750 \mathrm{~g}$ a.i./ha of sprayable pheromone by using a low-pressure hand sprayer. The top rate was undiluted and only applied for calibration of deposition (7 replicates). Densities of particles on the board were determined with a stereomicroscope. Magnetic stirring of particles was needed because of the buoyancy (flotation) of the pheromone product. Twenty-eight pre-treated boards (5 $\mathrm{m}$ separation) were baited with approximately $1 \mathrm{ml}$ of 1:1 macerated tuna (Bumblebee Foods, San Diego, CA, USA) and Karo Light Corn Syrup (ACH Food Companies, Memphis, TN, USA), centered on a plastic-coated card $(3 \times$ $5 \mathrm{~cm})$. Baits were protected from sunlight and heat with an inverted plastic plate $(25 \mathrm{~cm}$ diam.) suspended $15 \mathrm{~cm}$ above the ground. Counts of ants on the cards were made one hour after bait placement.

Impact on Traffic Rates To test the longevity of the sprayable pheromone, a bioassay that measured the effect of the pheromone formulation on Argentine ant trail traffic was conducted on a 6-m section of ant trail on an external painted cinder block wall in Hawai' $i$ Volcanoes National Park. Pheromone was sprayed from a height of $1 \mathrm{~m}$ onto five $9 \mathrm{~cm}$-diam. circular black craft paper discs (Pacon Corp., Appleton, WI, USA), for ca 0.5 s on 19 February 2008. Bioassays used treated half circles placed opposite each other, $2 \mathrm{~cm}$ either side of a vertical ant trail, at $0.5,2$, 4, 24, 48, and $72 \mathrm{~h}$ after treatment, then at approximately weekly intervals, for a total duration of 9 week. At each test time, a pre-treatment count of ant movement in a single direction along the trail was made for $1 \mathrm{~min}$ by using a bisected unsprayed disc placed along the trail as a control, followed by treated paper. For each observation (5 per date), two measurements of traffic rates were made, each $1 \mathrm{~min}$ apart, and pooled as pseudo-replicates (Hurlbert 1984) for analysis. It was expected that the short duration of the bioassay and the lack of complete disruption would enable 5 independent repeats at different locations along the trail but, to be certain, the data were analyzed for a downward trend in traffic. After the counts were completed, the half circles were removed from the trail and stored indoors at ambient temperature until the next test.

Small Field Plot Tests $\left(400 \mathrm{~m}^{2}\right)$ To test whether treatment of larger areas would facilitate more sustained trail and/or foraging disruption, trials were conducted in $20 \times 20 \mathrm{~m}$ plots, each with a $10 \times 10 \mathrm{~m}$ central square (Fig. 1). Eight plots, $80 \mathrm{~m}$ apart from each other, were randomly designated as treatment $(N=4)$ or as control $(N=4)$. Trail following and foraging of ants was measured within the central square; the outer area acted as a buffer zone for any influence of wind. Pheromone was applied at a rate of $375 \mathrm{~g}$ a.i./ha by using a 3.8 liter garden sprayer (RL Flo-Master ${ }^{\circledR}$, Root-Lowell Manufacturing Co., Lowell, MI, USA). The pheromone was divided into 10 equal portions so as to ensure uniform delivery of pheromone across the plot (Fig. 1). The sprayer was agitated continuously during application. Control plots were untreated.

Some $2.5 \mathrm{~h}$ prior to application of pheromone, five cards, baited with the 1:1 tuna-corn syrup mixture, were randomly placed within the $100 \mathrm{~m}^{2}$ centers of treatment and control plots (Fig. 1), The number of ants on each card and the presence or absence of trails to each card were determined $0.02 \mathrm{~d}$ before pheromone treatment, and $0.02,0.08,0.16,1,2,3,8,10,14,21,28$, and $35 \mathrm{~d}$ after treatment. Two of the 5 cards on each plot were randomly selected from those at which well-developed trails had been established ("fixed" locations). At later sampling dates, bait cards were placed at these fixed locations and at 3 new, randomly selected positions (Fig. 1). This differential placement of cards within plots was designed to challenge the ability of the ants to use established trails and to create new trails. Card placement simulated food resources that had either been previously identified by the ants or newly located on each sample date. The 2 fixed or 3 randomized cards from each plot were considered pseudo-replicates (Hurlbert 1984) and pooled for analysis.

The study was initiated on 29 January 2008, with two treatment and two control plots. The other 4 plots were started on 11 February 2008 because of poor weather.

Statistical Analysis Traffic rates and ant counts were logtransformed after initial inspection of the data indicated that this was warranted to stabilize the variance. Disruption in the bioassay and small plot test was calculated as $=100-$ (count in the Treatment / count in the Control) * 100. Twoway ANOVA on log-transformed counts of ants was used to analyze the traffic rates for main effects (time and treatment) testing the longevity of the pheromone. Logtransformed counts of ants at baits in the micro-plot experiment were analyzed using two-way ANOVA. The experimental design for the small-plot test was a random- 
ized complete block with two factors (treatment and bait card location) at two levels (control, treatment; fixed, random). A general linear model was conducted on logtransformed counts of ants at bait cards to stabilize the variance. The proportion of ant trails at the bait cards in the randomized and fixed plots was predicted using binary logistic regression (Quinn and Keough 2002). This predicted the probability of trail presence at the baits. The dependent-response variable was the presence or absence of ant trails to the cards, modeled using three explanatory factors: randomized/fixed cards, time, and treatment. The data were modeled against reference categories for each explanatory factor; reference categories, randomized = "fixed", time = "before", treatment = "no pheromone". The predicted odds ratio, $\exp (\beta)$, indicated the odds of trail presence for the explanatory factors compared to their respective reference categories (see Stringer et al. 2007 for further explanation). For example, if the odds ratio, $\exp (\beta)$, is 20 for a point in time, then the odds of trail presence is 20 times greater than the reference time (before). A value of 1 would indicate that trail presence after application did not differ from that before. Only the main effects were modeled, as there were no significant interaction effects. Data were analyzed in GenStat (GenStat 2007) and SAS (2004).

\section{Results}

Pre-treated Micro-plot Disruption No evidence was found for short distance disruption in recruitment of ants to bait cards $\left(F_{3,24}=2.47, P=0.09\right.$, mean \pm standard deviation $89.6 \pm$ 49.7 ants/card). There was no correlation between ant counts and the number of particles found on sample papers $\left(r^{2}=0.15\right.$; range $0-6$ particles per $\left.38.5 \mathrm{~cm}^{2}\right)$.

Bioassay of Impact on Traffic Rates Two-way ANOVA revealed a significant effect for treatment $\left(F_{1,136}=142.3\right.$, $P<0.001)$ and time $\left(F_{16,136}=3.41, P=0.001\right)$, with no significant interaction between the two factors. There was no impact of untreated cards on traffic rates (number of ants/min) over the course of the study, and no trend in traffic rate among repetitions $(P>0.999, d f=84)$. A significant downward trend in traffic rate with time since pheromone treatment was found $(\%$ reduction in traffic over time $=-0.5083 \mathrm{x}+72.92$, where $\mathrm{x}=$ dose of pheromone treatment; $r^{2}=0.63, P<0.01$ ) (Fig. 2).

Small Field Plot Tests $\left(400 \mathrm{~m}^{2}\right)$ Argentine ant trails were significantly disrupted shortly after pheromone application and up to 14 days later, measured by a reduction in the presence of visible trails in plots with both types of bait

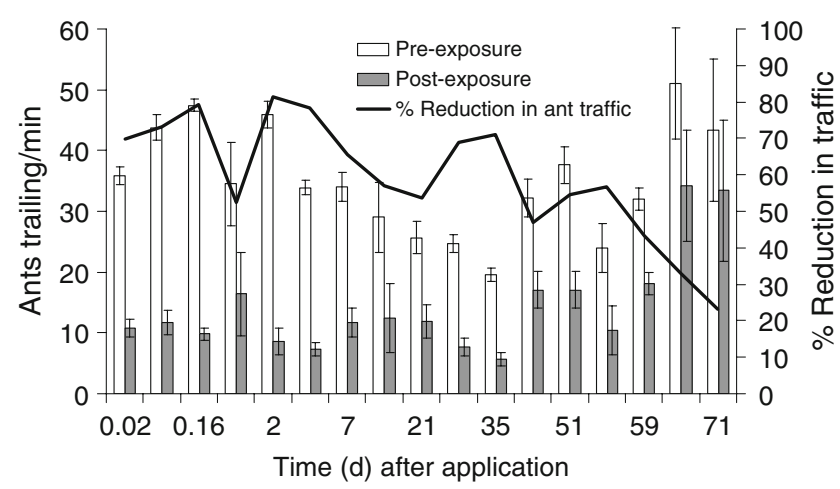

Fig. 2 Effect of application of micro-encapsulated synthetic trail pheromone, $(Z)$-9-hexadecenal, on Argentine ant trail-following over time; measured as mean $( \pm$ SEM) traffic rates (left axis) and \% reduction (compared to controls, pre-exposure) of ant counts, postexposure (right axis, line)

locations and treatments (Fig. 3). Following pheromone application, there was a significant reduction in trail presence, with the odds ratio being 28 times less than for trail presence before pheromone application. The predicted odds of trail presence at randomized baits was eight times lower than at fixed bait positions, regardless of treatment (Table 1).

Randomizing the location of baited sites influenced ant counts at baits $\left(F_{(1,6)}=19.25, P<0.005\right)$, with a reduction in worker number in the treated plots (Fig. 4). However, inspection of results on individual dates showed that the pheromone treatment disrupted ant trail formation on cards (as evidenced by the proportions of cards with trails) longer than it disrupted the counts of ants on cards (Figs. 3, 4, 5). Bait predation by introduced mongoose, Herpestes javanicus, occurred in several plots on Day 8. No error bars are shown on this day because of the resultant lack of degrees of freedom.

\section{Discussion}

We have demonstrated, using a micro-encapsulated trail pheromone formulation in a natural ecosystem, that significant disruption of trail following by Argentine ants is possible over at least a 14-day period. This is an improvement in longevity of disruption over the wax-based dispersible formulating originally tested, which disrupted visual trails and foraging at bait cards in $4-\mathrm{m}^{2}$ plots for only $24 \mathrm{~h}$ (Suckling et al. 2008). We also were able to demonstrate significant disruption of foraging by Argentine ant workers for bait cards.

Our bioassay that examined traffic rates proved to be a robust and reliable measure of trail disruption from a point source (Suckling et al. 2008; Tanaka et al. 2009). The 


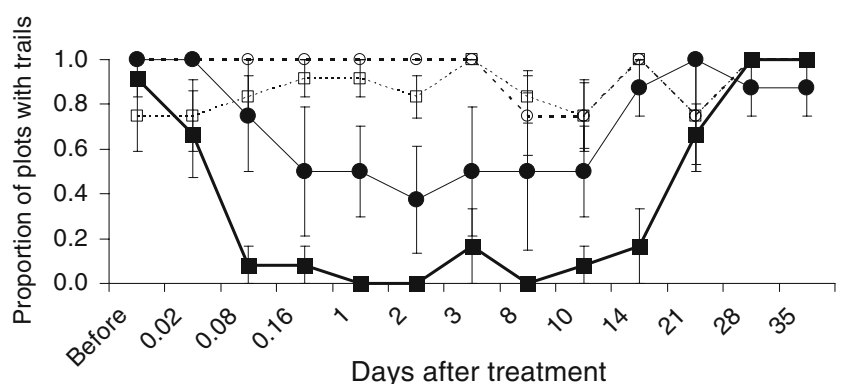

- - $\odot$. - Control /Fixed baits $\quad \ldots \boxminus \cdots$. Control /Randomized baits - Treatment/Fixed baits $\rightarrow$-Treatment/Randomized baits

Fig. 3 Proportion of plots with visible Argentine ant trails before and after the $400-\mathrm{m}^{2}$ test areas were treated with micro-encapsulated synthetic trail pheromone or left as untreated control. Periodic $1 \mathrm{~min}$ observations for presence of trails were made, commencing $30 \mathrm{~min}$ after treatment, near baits placed repeatedly in the same location (fixed baits) or replaced at random positions (randomized baits). Bars indicate one standard error

results showed that the treated bioassay cards, stored in the absence of sunlight or rainfall, maintained their efficacy at disrupting trail following for many weeks. Testing under less favorable conditions should be carried out to determine the robustness of the formulation in the field.

The micro-plot experiments offered a minimum walking distance of $6.3 \mathrm{~cm}$ from the edge of the sprayed area to the central bait card for disruption. That complete disruption was not achieved under these conditions, suggests that ant trails were formed near the treated boards, and that foraging

Table 1 Binary logistic regression on the presence of Argentine ant trails modeled on explanatory factors of randomized/fixed bait cards, treatment, and time. Reference categories for explanatory factors: randomized/fixed bait cards = "fixed", treatment = "no pheromone' and time = "before"; $\exp (\beta)=$ predicted odds ratio

\begin{tabular}{lrlllr}
\hline Factor & $\beta$ & SE & Wald & $P$ & $\exp (\beta)$ \\
\hline Randomized & -2.054 & 0.340 & -6.040 & $<.001$ & 0.128 \\
Treated & -3.323 & 0.363 & -9.170 & $<.001$ & 0.036 \\
Time (days) & & & & & \\
0.021 & -0.831 & 0.757 & -1.100 & 0.272 & 0.436 \\
0.08 & -2.501 & 0.738 & -3.390 & $<.001$ & 0.082 \\
0.16 & -2.688 & 0.738 & -3.640 & $<.001$ & 0.068 \\
1 & -2.475 & 0.784 & -3.160 & 0.002 & 0.084 \\
2 & -3.232 & 0.743 & -4.350 & $<.001$ & 0.039 \\
3 & -2.310 & 0.737 & -3.130 & 0.002 & 0.099 \\
8 & -2.913 & 0.947 & -3.080 & 0.002 & 0.054 \\
10 & -3.408 & 0.745 & -4.570 & $<.001$ & 0.033 \\
14 & -1.712 & 0.738 & -2.320 & 0.020 & 0.181 \\
21 & 0.244 & 0.868 & 0.280 & 0.778 & 1.277 \\
28 & 1.610 & 1.160 & 1.390 & 0.164 & 5.025 \\
35 & 1.610 & 1.160 & 1.390 & 0.164 & 5.025 \\
Constant & 6.295 & 0.784 & 8.03 & $<.001$ & 542.0 \\
\hline
\end{tabular}

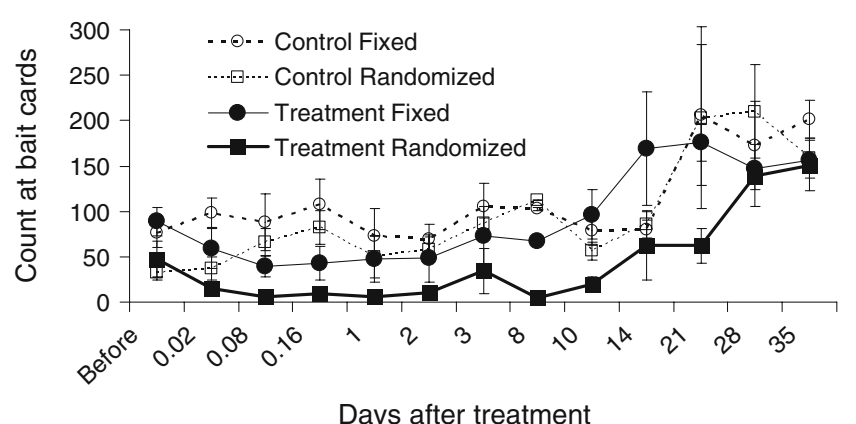

Fig. 4 Mean ( \pm SEM) count of Argentine ants at bait cards before (control) and after synthetic trail pheromone treatment. Cards were placed in the field, repeatedly either at the same location (fixed) or randomly (randomized) within the central $10 \times 10 \mathrm{~m}$ of the plot, $2 \mathrm{~h}$ before counts. Bars indicate one standard error

ants regrouped onto trails in the vicinity of the bait. Argentine ants can orientate using cues other than trail pheromones to find food resources. For instance, they are known to use food odors (Wolf and Wehner 2000; Stanley et al. 2008), but not vision (Aron et al. 1993), to orient toward food sources. As trail following from the edge of the disrupted boards to the central food was unsuccessful, it appears likely that multiple individual discoveries of the food source were made, rather than a single discovery (or few discoveries) complemented by recruitment through trail pheromone.

The effect of disruption in the larger plots was less pronounced in the situation in which baits were replaced in the same locations (fixed), compared to when their positions were re-randomized. This suggests that ant nests may have learned the location of the fixed baits by associating different cues such as food olfactory cues (Wolf and Wehner 2000) or different pheromones (Dussutour et al. 2009) with the resource. It is not clear whether the responses of the ants to the fixed or randomized baits in this study are typical of ant responses to food supplies such as floral nectar or honeydew from homopterans. Finding of

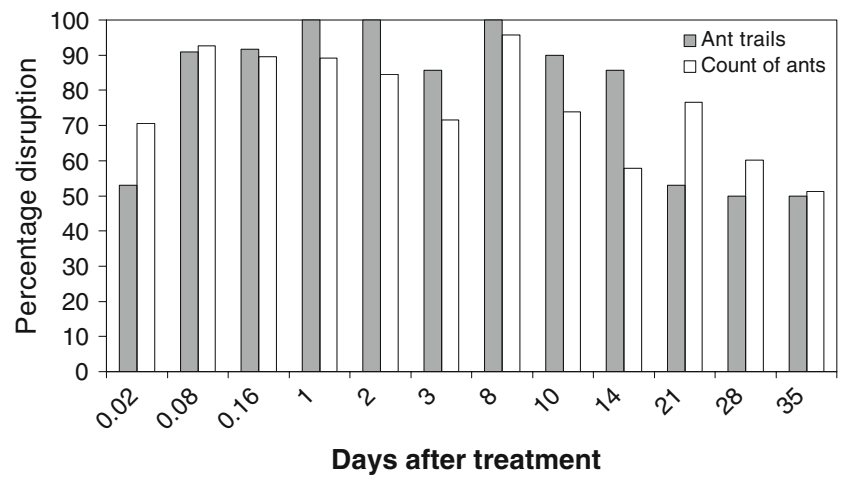

Fig. 5 Percentage trail pheromone disruption (relative to untreated controls) of Argentine ants in small plots $\left(400 \mathrm{~m}^{2}\right)$ over time, as measured by reduction in presence of trails and ant counts at randomized bait cards 
the randomized bait cards probably represents the opportunistic foraging efforts of the nest (i.e., the nest's ability to detect and use new food sources); reduced trail formation and forager numbers to such opportunistic food sources likely results in lesser utilization, and possibly an impact of nest productivity.

With our demonstration of the feasibility of long-duration disruption of Argentine ant trail following using sprayable pheromone, future research should concentrate on improving the efficacy of the method through studying the mechanisms involved both in trail following and disruption of the behavior. Additionally, disruption could be improved by the identification and utilization of other compounds involved in trail following (Cavill et al. 1979). We will continue examining the potential of disruption of pheromone trail integrity as a stand-alone pest management tactic against Argentine ants and as a tactic integrated with other control methods.

Acknowledgements This work was supported by the New Zealand Foundation for Research Science and Technology ("Managing Invasive Hymenoptera", contract C06X0601) and the U.S. Geological Survey and National Park Service ("Park-Oriented Biological Support"). Thanks also to "Better Border Biosecurity" (www.b3nz.org). We thank J. Cappadonna, M. Euaparadorn, M. Stelmach, C. Pinzari, G. Ryman, and C. Stephen for help conducting field trials. Suterra LLC kindly provided the formulation at our request. Any use of trade, product, or firm names in this publication is for descriptive purposes only and does not imply endorsement by the U.S. Government.

\section{References}

Aron, S., Beckers, R., Deneubourg, J. L., and Pasteels, J. M. 1993. Memory and chemical communication in the orientation of 2 mass-recruiting ant species. Insect. Soc. 40:369-380.

Cavill, G. W. K., Robertson, P. L., and Davies, N. W. 1979. An Argentine ant Iridomyrmex humilis aggregation factor. Experientia 35:989-990.

Christian, C. E. 2001. Consequences of a biological invasion reveal the importance of mutualism for plant communities. Nature 413:635-639.

Cole, F. R., Medeiros, A. C., Loope, L. L., and Zuehlke, W. W. 1992. Effects of the Argentine ant on arthropod fauna of Hawaiian high-elevation shrubland. Ecology 73:1313-1322.

Dussutour, A., Nicolis, S. C., ShePARD, G., BeEkMan, M., and SUMPTER, D. J. T. 2009. The role of multiple pheromones in food recruitment by ants. J. Exp. Biol. 212:2337-2348.

EL-SAYED, A. M. 2009. The Pherobase: Database of Insect Pheromones and semiochemicals. http://www.pherobase.com Accessed 23 February 2009.

GENSTAT. 2007. GenStat tenth edition, V 10.1.0.71, Lawes Agricultural Trust, VSN International Ltd.

GILLESPIE, R. G., and REIMER, N. 1993. The effect of alien predatory ants (Hymenoptera: Formicidae) on Hawaiian endemic spiders (Araneae: Tetragnathidae). Pac. Sci. 47:21-33.

GreenBerG, L., KLOTZ, J. H., and RUST, M. K. 2006. Liquid borate bait for the control of the Argentine ant, Linepithema humile, in organic citrus (Hymenoptera: Formicidae). Fla. Entomol. 89:469-474.
Holway, D. A. 1999. Competitive mechanisms underlying the displacement of native ants by the invasive Argentine ant. Ecology 80:238-251.

Holway, D. A., Lach, L., Suarez, A. V., Tsutsui, N. D., and Case, T. J. 2002. The causes and consequences of ant invasions. Annu. Rev. Ecol. Syst. 33:181-233.

Hooper-Bui, L. M., and Rust, M. K. 2000. Oral toxicity of abamectin, boric acid, fipronil, and hydramethylnon to laboratory colonies of Argentine ants (Hymenoptera: Formicidae). J. Econ. Entomol. 93:858-864.

HumAN, K. G., and GordON, D. M. 1996. Exploitation and interference competition between the invasive Argentine ant, Linepithema humile, and native ant species. Oecologia 105:405-412.

Human, K. G., and Gordon, D. M. 1997. Effects of Argentine ants on invertebrate biodiversity in northern California. Conserv. Biol. 11:1242-1248.

HuRlBerT, S. H. 1984. Pseudoreplication and the design of ecological experiments. Ecol. Monogr. 54:187-211.

Itioka, T., and InOUE, T. 1996. Density-dependent ant attendance and its effects on the parasitism of a honeydew-producing scale insect, Ceroplastes rubens. Oecologia 106:448-454.

Klotz, J., Greenberg, L., and VenN, G. 2000. Evaluation of two hydramethylnon granular baits for control of Argentine ant (Hymenoptera: Formicidae). Sociobiology 36:201-207.

KRUSHELnYCKY, P. D., and REIMER, N. J. 1998. Bait preference by the Argentine ant (Hymenoptera: Formicidae) in Haleakala National Park, Hawaii. Environ. Entomol. 27:1482-1487.

LiEBHERR, J. K., and KRUSHELNYCKY, P. D. 2007. Unfortunate encounters? Novel interactions of native Mecyclothorax, alien Trechus obtusus (Coleoptera: Carabidae), and Argentine ant (Linepithema humile, Hymenoptera: Formicidae) across a Hawaiian landscape. J. Insect Conserv. 11:61-73.

Moreno, D. S., HANey, P. B., and LUCK, R. F. 1987 Chlorpyrifos and diazinon as barriers to Argentine ant (Hymenoptera: Formicidae) foraging on citrus trees. J. Econ. Entomol. 80:208-214.

QuinN, G. P., and KeOUgh, M. J. 2002. Experimental Design and Data Analysis for Biologists. University Press, Cambridge, UK, pp. 360-371.

Robinson, S. W., and Cherrett, J. M. 1978. The possible use of methyl 4-methylpyrrole-2-carboxylate, an ant trail pheromone, as a component of an improved bait for leaf-cutting ant (Hymenoptera: Formicidae) control. B. Entomol. Res. 68:159-170.

SAS Institute Inc. 2004. SAS/IML 9.1 User's Guide. Cary, NC: SAS Institute Inc.

Shorey, B. H., Gaston, L. K., Gerber, R. G., Phillips, P. A., and WooD, D. L. 1992 Disruption of foraging by Argentine ants, Iridomyrmex humilis (Mayr) (Hymenoptera: Formicidae), in citrus trees through the use of semiochemicals and related chemicals. J. Chem. Ecol. 18:2131-2142.

Stanley, M., Ward, D., Harris, R., Arnold, G., Toft, R., and REES, J. 2008. Optimizing pitfall sampling for the detection of Argentine ants, Linepithema humile (Hymenoptera: Formicidae). Sociobiology 51:461-472.

STELINSKI, L. L., MCGHEE, P., HAAS, M., IL'TCHEV, A. L., and GUT, L. J. 2007. Sprayable microencapsulated sex pheromone formulations for mating disruption of four tortricid species: effects of application height, rate, frequency, and sticker adjuvant. J. Econ. Entomol. 100:1360-1369.

StRINGER, L. D., HAYwoOd, J., and LeSTER, P. J. 2007. The influence of temperature and fine-scale resource distribution on resource sharing and domination in an ant community. Ecol. Entomol. 32:732-740.

SuCKLING, D. M. 2000. Issues affecting the use of pheromones and other semiochemicals in orchards. Crop Prot. 19:677-683.

SuCKLING, D. M., and ANGerilli, N. P. D. 1996. Pheromone point source distribution affects spike frequency and communication 
disruption of Epiphyas postvittana (Lepidoptera: Tortricidae). Environ. Entomol. 25:101-108.

Suckling, D. M., Green, S. R., GibB, A. R., and KarG, G. 1999. Predicting atmospheric concentration of pheromone in treated apple orchards. J. Chem. Ecol. 25:117-139.

Suckling, D. M., PeCK, R. W., Manning, L. M., Stringer, L. D., CAPPADONNA, J., and El-SAYED, A. M. 2008. Pheromone disruption of Argentine ant trail integrity. J. Chem. Ecol. 34:1602-1609.

Tanaka, Y., Nishisue, K., Sunamura, E., Suzuki, S., SaKamoto, H., FUKUMOTO, T., TERAYAMA, M., and TATSUKI, S. 2009. Trail-following disruption in the invasive Argentine ant with a synthetic pheromone component (Z)-9-hexadecenal. Sociobiology 54:139-152.

TATsuki, S., Teryama, M., TANAKA, Y., and Fukumoto, T. 2005. Behaviour-disrupting agent and behaviour disrupting method of Argentine ant. Patent pub. no. US2005/0209344A1.
VAN Vorhis Key, S. E., and BaKer, T. C. 1982. Specificity of laboratory trail following by the Argentine ant, Iridomyrmex humilis (Mayr), to (Z)-9-hexadecenal, analogs, and gaster extract. J. Chem. Ecol. 8:1057-1063.

VAN Vorhis Key, S. E., Gaston, L. K., and BaKeR, T. C. 1981. Effects of gaster extract trail concentration on the trail following behaviour of the Argentine ant, Iridomyrmex humilis (Mayr). J. Insect Physiol. 27:363-370.

VEGA, S. J., and RUST, M. K. 2001. The Argentine ant —a significant invasive species in agricultural, urban and natural environments. Sociobiology 37:3-25.

WOLF, H., and WeHNER, R. 2000. Pinpointing food sources: Olfactory and anemotactic orientation in desert ants Cataglyphis fortis. J. Exp. Biol. 203:857-868.

WrigHT, R. H. 1964. After pesticides-what? Nature 204:121-125. 